\title{
Combining caesium-137 measurements and suspended sediment load data to investigate the sediment response of a small catchment in southern Italy
}

\author{
PAOLO PORTO ${ }^{1,2}$, DESMOND E. WALLING ${ }^{2}$, CARMELO LA SPADA ${ }^{1} \&$ \\ NICOLA MALLIMO ${ }^{1}$ \\ 1 Dipartimento di Agraria, Università degli Studi Mediterranea, Località Feo di Vito, Reggio Calabria, Italy \\ paolo.porto@unirc.it \\ 2 College of Life and Environmental Sciences, University of Exeter, Amory Building, Rennes Drive, Exeter EX4 4RJ, UK
}

\begin{abstract}
A long-term measurement programme was operated in southern Italy during the 1960s and 1970s, to provide information on the suspended sediment yields from the main river basins. Information obtained for the rivers of Calabria suggests that suspended sediment yields in this area are relatively low. However, there is evidence that the intensity of land degradation within the upstream catchments is substantially higher than suggested by the values of specific sediment yield and there is a need to explore the relationship between on-site soil loss and downstream sediment yield more closely. Monitoring time-integrated erosion rates over large areas has traditionally required extensive long-term measurement programmes employing experimental plots. The fallout radionuclide caesium-137 $\left({ }^{137} \mathrm{Cs}\right)$ offers an alternative means of documenting medium-term rates of soil loss. This paper describes the use of ${ }^{137} \mathrm{Cs}$ measurements and the available sediment load data to explore the links between soil erosion, sediment redistribution and storage, and sediment output for a medium-scale $\left(41.3 \mathrm{~km}^{2}\right)$ catchment in Calabria. Data available from a sediment load monitoring programme undertaken at the catchment outlet during 1962-1977 have been used to estimate the longer-term catchment sediment yield. This estimate has been combined with information provided by the ${ }^{137} \mathrm{Cs}$ measurements, to establish a medium-term sediment budget for the catchment. The results provided by the ${ }^{137} \mathrm{Cs}$ measurements indicate that the catchment is subject to much higher rates of soil loss and land degradation than suggested by its specific sediment yield. These findings are consistent with the results obtained for other catchments in Calabria for which both ${ }^{137} \mathrm{Cs}$ derived erosion rates and measured sediment yields are available.
\end{abstract}

Key words sediment load; caesium-137; soil redistribution; erosion; sedimentation; sediment budget; Italy

\section{INTRODUCTION}

In semi-arid Mediterranean areas, the construction of small dams aimed at providing water for domestic supply, livestock, or irrigation has generated a need for information on sediment yields for the main river basins. In southern Italy, a long-term monitoring programme was initiated by the National Hydrographic Service during the first half of the last century to address this need. The information obtained for the rivers in Calabria during the 1960s and 1970s documented relatively low suspended sediment yields in this area. However, recent studies in this region have demonstrated that the low values of specific sediment yield derived from this monitoring programme obscure the existence of appreciable erosion rates in many areas of the catchments involved (Porto et al., 2009b). To better understand the relationship between the sediment yield at a catchment outlet, and rates of sediment mobilisation and transfer within the catchment, there is a need to employ alternative methods capable of providing information on soil redistribution rates for large areas. In recent years, the fallout radionuclide caesium-137 $\left({ }^{137} \mathrm{Cs}\right)$ has been increasingly used to document rates of soil redistribution associated with sheet erosion both as an alternative to conventional measurements, and for calibrating physically-based soil erosion models (Di Stefano et al., 2000; Walling, 1998; Porto et al., 2001). This paper reports the results of a study where ${ }^{137} \mathrm{Cs}$ measurements were employed within a medium-scale $\left(41.3 \mathrm{~km}^{2}\right)$ catchment in southern Italy, with the aim of assembling information on soil erosion and redistribution on the catchment slopes. Data available from suspended sediment monitoring undertaken at the catchment outlet during the 1960s and 1970s have been used to estimate the contemporary sediment yield. This estimate has been combined with the information provided by the ${ }^{137} \mathrm{Cs}$ measurements to establish a sediment budget for the catchment. The results confirm that ${ }^{137} \mathrm{Cs}$ measurements are valuable for quantifying both erosion and sediment redistribution within a catchment and therefore, for establishing its sediment budget. 


\section{THE STUDY AREA}

The Melito catchment (Fig. 1) is located in Calabria (southern Italy) in the vicinity of the Sila National Park. The catchment has a drainage area of $41.3 \mathrm{~km}^{2}$ and ranges in altitude from $1300 \mathrm{~m}$ a.s.l. at its highest point (Colle San Domenico) to $324 \mathrm{~m}$ a.s.l. at the catchment outlet (Olivella) where the main channel flows into the larger River Corace. Geologically, the Melito catchment is underlain by granitoid sand and intermediate and high-grade metamorphic rocks, typical of the Aspromonte Mountains that are part of the Calabro-Peloritan arc, a region with the highest tectonic activity in Europe. Detailed soil surveys undertaken in this catchment have shown that the soils developed on these rock types are characterised by a range of textures, although sandy and silt-sandy soils are dominant. The catchment is mainly uncultivated and large areas are covered by pines (Pinus nigra ssp. laricio, P. sylvestris, P. leucodermis) beech (Fagus sylvatica L.) and different species of oak (Quercus cerris, $Q$. pubescens, $Q$. frainetto, $Q$. petrea, $Q$. robur). The rainy season extends from September to April, and the mean annual rainfall for the period 1962-2000 measured at Umbri (altitude $885 \mathrm{~m}$ a.s.1., $39^{\circ} 01^{\prime} 31^{\prime \prime} \mathrm{N}, 16^{\circ} 33^{\prime} 24^{\prime \prime} \mathrm{E}$ ), is $\sim 1127 \mathrm{~mm}$ (SIMI, 1920-2000).

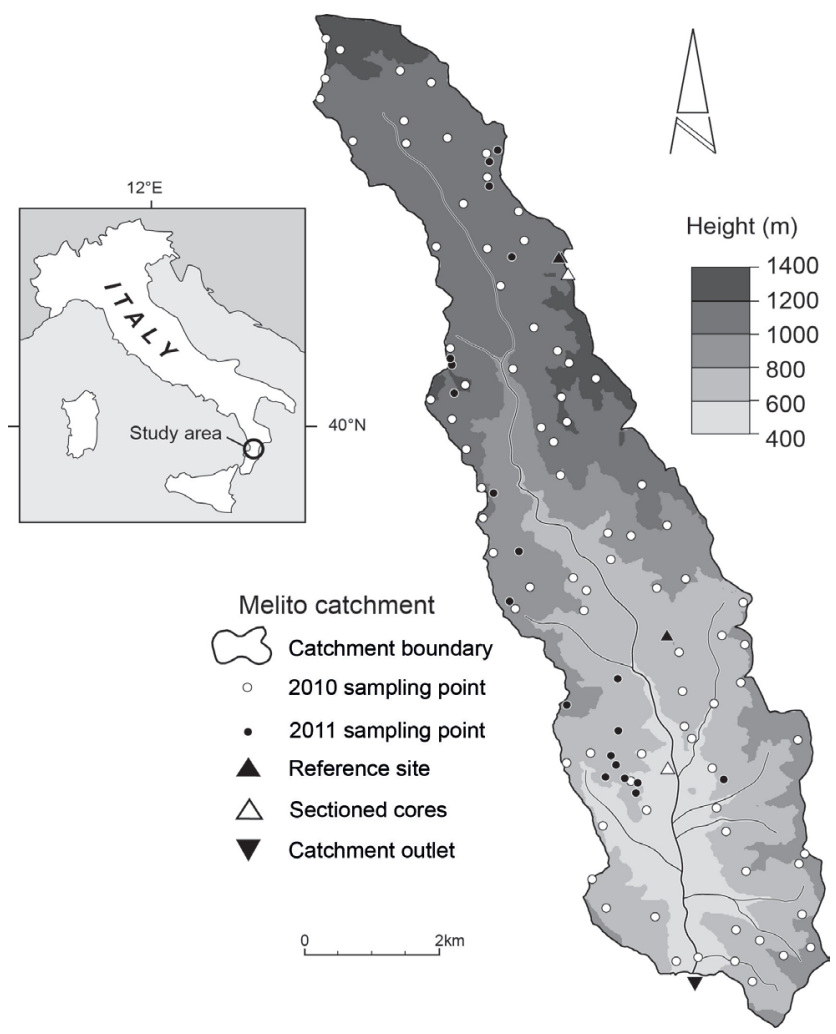

Fig. 1 The study catchment and the soil sampling points.

In 1983 the Melito catchment was identified as the preferred site for a proposed dam (with a reservoir storing more than 100 million $\mathrm{m}^{3}$ ) to provide water for domestic supply, livestock, and irrigation within the local area. To date, this dam has not been built, although construction is now in progress. To support the design of this and other dams in the region, the Italian Hydrographic Service (SIMI) undertook measurements of rainfall, runoff, and suspended sediment concentration at the catchment outlet during the period 1962-1977. During this monitoring period, the annual specific suspended sediment yield, derived from the sediment concentration measurements, ranged from $5.4 \mathrm{t} \mathrm{km}^{-2}$ year $^{-1}$ in 1970 to $205 \mathrm{t} \mathrm{km}^{-2}$ year $^{-1}$ in 1976, with a mean annual value of $40 \mathrm{t} \mathrm{km}^{-2}$ year ${ }^{-1}$ (Fig. 2). Porto et al. (2006) documented higher values of sediment yield (ranging from 760 to $2080 \mathrm{t} \mathrm{km}^{-2}$ year $^{-1}$ ) for the coastal areas of the same region (see also Cinnirella et al., 1998; Porto et al., 2009a). However, the values reported in this work, although considerably lower, can be regarded as representative of the mountain areas of the Serre Massif (see Porto et al., 2009b). 


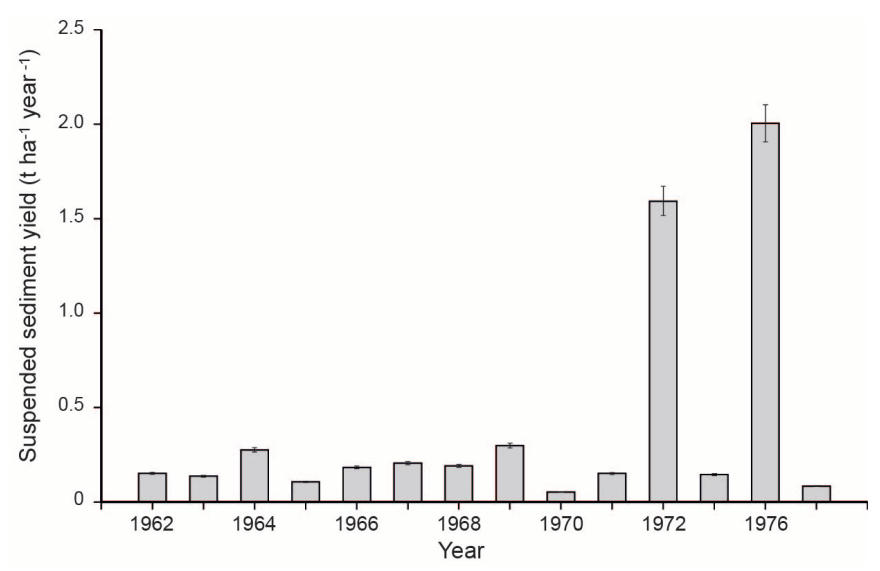

Fig. 2 Annual suspended sediment yields from the Melito catchment.

\section{THE SAMPLING AND ANALYSIS PROGRAMME}

Soil sampling for ${ }^{137} \mathrm{Cs}$ analysis in the Melito catchment involved three separate campaigns. The first, undertaken in 2010, focused on establishing the magnitude and spatial distribution of soil redistribution rates within the catchment. During this campaign replicate bulk soil cores were collected at 80 sites (Fig. 1) using an 11-cm diameter steel core tube inserted to a depth of $\geq 45 \mathrm{~cm}$. The second campaign, undertaken at the beginning of 2011, aimed to establish both the magnitude and the depth distribution of the ${ }^{137} \mathrm{Cs}$ inventories at three undisturbed reference sites with minimum slope. These reference sites were located in small clearings between the trees (Fig. 1). At each site, eight separate cores were collected from an area of approx. $25 \mathrm{~m}^{2}$, in order to account for micro-scale variability in the reference inventory (cf. Owens \& Walling, 1996). The cores were collected using an 11-cm diameter steel core tube inserted to a depth of $50 \mathrm{~cm}$. Each core was sectioned using the same depth increments, which ranged from 1 to $4 \mathrm{~cm}$, and the individual depth increments from the eight cores were bulked. The third campaign, undertaken in late 2011, aimed to document the variability of the ${ }^{137} \mathrm{Cs}$ depth distribution over the study area. In this case, as with the reference site sampling, eight separate cores were collected from two representative sites to obtain identify erosional and depositional areas. These cores were sectioned as before. During the same campaign, additional replicate bulk soil cores (Fig. 1) were collected from 20 sites characterised by marked variability in vegetative cover or topography, increasing the number of bulk cores to 100 .

All bulk core and incremental depth samples collected in the catchment were oven dried at $105^{\circ} \mathrm{C}$ for $48 \mathrm{~h}$, disaggregated, and dry sieved to separate out the $<2 \mathrm{~mm}$ fraction. A representative sub-sample of this fraction (approx. $0.1 \mathrm{~kg}$ ) was packed into a plastic sample container for the determination of ${ }^{137} \mathrm{Cs}$ activity by gamma spectroscopy in the Radiometry Laboratory of the Geography Department at the University of Exeter. Activities of ${ }^{137} \mathrm{Cs}$ in the soil samples were measured using a high-resolution low energy coaxial HPGe detector coupled to an amplifier and PC-based data collection system. Counting times typically were around $80000 \mathrm{~s}$, providing results with an analytical precision of about $\pm 10 \%$, at the $95 \%$ confidence level. The efficiency of the detection system was calibrated using standard samples prepared by adding known amounts of certified liquid radionuclide standards to representative soil samples. The ${ }^{137} \mathrm{Cs}$ activities in the samples were obtained from the gamma counts at $662 \mathrm{keV}$.

\section{RESULTS}

\section{${ }^{137}$ Cs measurements at the reference site}

The mean ${ }^{137} \mathrm{Cs}$ inventory obtained for the composite sectioned cores collected from the three reference sites was $4706 \mathrm{~Bq} \mathrm{~m}^{-2}$ (see Table 1). Since there was no evidence that the magnitude of the inventories measured at the reference sites was influenced by altitude, and the available records indicate that there was little variation in mean annual rainfall across the study area, this mean value 
Table $\mathbf{1}^{137} \mathrm{Cs}$ inventories for the Melito catchment.

\begin{tabular}{lllll}
\hline $\begin{array}{l}\text { Reference inventory } \\
\text { Mean } \\
\left(\mathrm{Bq} \mathrm{m}^{-2}\right)\end{array}$ & $\begin{array}{l}\text { Range }( \pm 10 \% \text { uncertainty) } \\
\left.(\mathrm{Bq} \mathrm{m})^{-2}\right)\end{array}$ & $\begin{array}{l}\text { Inventories } \\
\text { Mean } \\
\left(\mathrm{Bq} \mathrm{m}^{-2}\right)\end{array}$ & $\begin{array}{l}\text { Range catchment } \\
\left.(\mathrm{Bq} \mathrm{m})^{-2}\right)\end{array}$ & $\begin{array}{l}\text { Standard deviation } \\
\left(\mathrm{Bq} \mathrm{m}^{-2}\right)\end{array}$ \\
\hline 4706 & $4235-5177$ & 2565 & $272-8745$ & 1565 \\
\hline
\end{tabular}

has been applied to the entire catchment. The average depth distribution of ${ }^{137} \mathrm{Cs}$ associated with these sectioned cores is illustrated in Fig. 3(a), where the depth scale is presented as cumulative mass, to avoid the need to account for downcore variations in soil bulk density. This depth distribution is typical of an undisturbed site (Walling \& Quine, 1993), with approx. 90\% of the total inventory occurring in the top $10 \mathrm{~cm}$, and a sharp decline in activity below this depth.

The values for the ${ }^{137} \mathrm{Cs}$ inventories obtained for the 100 bulk cores collected from the study catchment ranged from 272 to $8745 \mathrm{~Bq} \mathrm{~m}^{-2}$, with a mean value of $2565 \mathrm{~Bq} \mathrm{~m}$ (Table 1). A measurement precision of $\pm 10 \%$ at the $95 \%$ level of confidence has been assumed for the estimate of the ${ }^{137} \mathrm{Cs}$ reference inventory for the study catchment. As a result, measured inventories for individual sampling sites must fall either above or below this range to be indicative of either erosion or deposition. The results indicate that $6 \%$ of the ${ }^{137} \mathrm{Cs}$ inventory values obtained for the individual sampling points were not significantly different from the reference value, suggesting that those sampling points were essentially stable, with no significant erosion or deposition occurring. However, $87 \%$ of the inventories were significantly lower than the reference value, indicating erosion, and 7\% were significantly greater, indicating deposition. Figures 3(b) and (c) relate to the two representative erosional and depositional sites within the study catchment where depth incremental sampling was undertaken. The ${ }^{137} \mathrm{Cs}$ inventory associated with the depth profile shown in Fig. 3(b) is $1722 \mathrm{~Bq} \mathrm{~m}^{-2}$. This is substantially lower than the reference inventory and is therefore indicative of erosion. In contrast, the depth profile presented in Fig. 3(c), with an inventory of $6838 \mathrm{~Bq} \mathrm{~m}^{-2}$ that exceeds the reference value, is indicative of deposition. The significant reduction in inventory evident for $87 \%$ of the cores indicates that most of the sampling points have experienced erosion over the period since the commencement of ${ }^{137} \mathrm{Cs}$ fallout in the mid-1950s.

a)

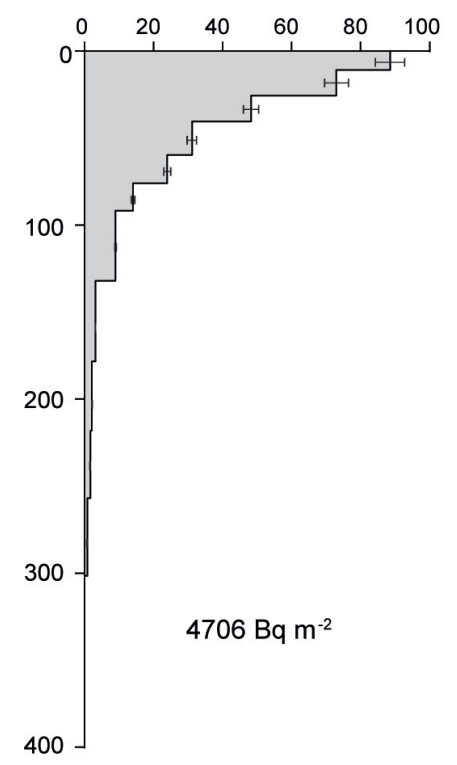

b)

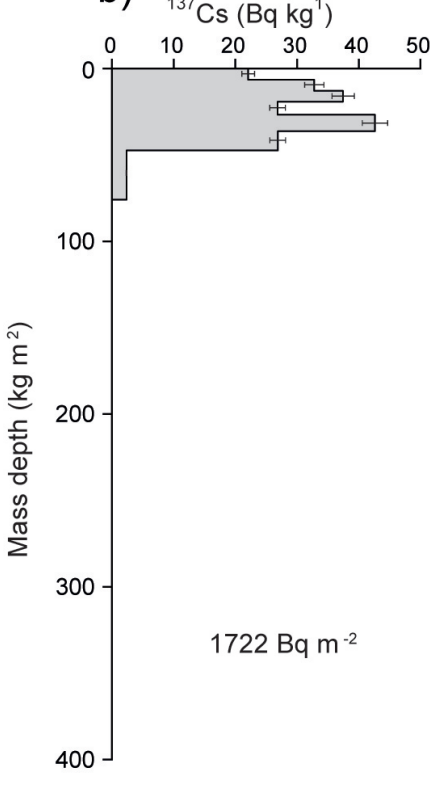

c)

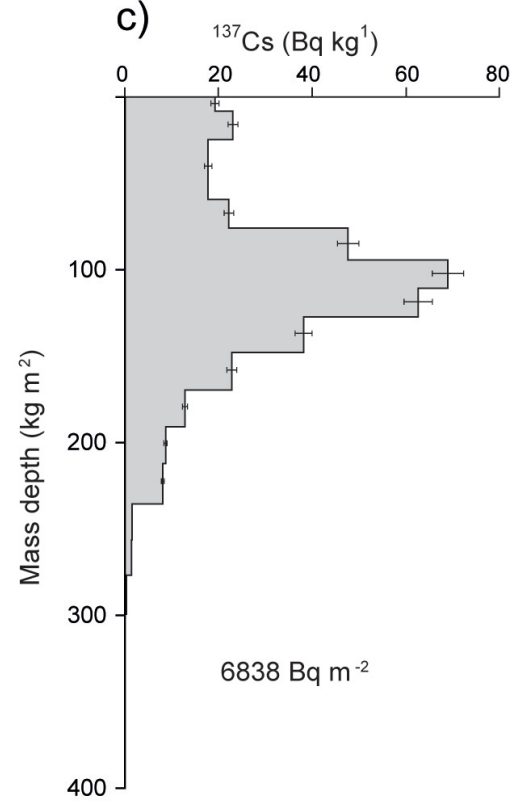

Fig. 3 The ${ }^{137} \mathrm{Cs}$ depth distributions for the reference site (a), an eroding site (b), and a depositional site (c) within the Melito catchment. The error bars depict the $95 \%$ confidence limits of the measured radionuclide activities. 


\section{Using ${ }^{137} \mathrm{Cs}$ to estimate soil redistribution rates}

In this study, a diffusion and migration model has been used for the purpose of estimating the soil redistribution rates indicated by the ${ }^{137} \mathrm{Cs}$ inventories measured at the 100 bulk core sampling sites (see Walling \& He, 1999; Walling et al., 2002). Using this approach, the post depositional redistribution of the ${ }^{137} \mathrm{Cs}$ fallout is assessed using a simplified one dimensional transport model in the form proposed by Porto et al. (2003):

$$
C_{e}\left(x, t, t^{\prime}\right)=e^{-\lambda\left(t-t^{\prime}\right)} \int_{0}^{\infty} \frac{I\left(t^{\prime}\right)}{H} e^{-\frac{y}{H}}\left\{\left[e^{-\frac{[(x+E)+y]^{2}}{4 D\left(t-t^{\prime}\right)}}+e^{-\frac{[(x+E)-y]^{2}}{4 D\left(t-t^{\prime}\right)}}\right] \frac{1}{\sqrt{4 \pi D\left(t-t^{\prime}\right)}}\right\} \mathrm{d} y
$$

where:

$C_{e}\left(x, t, t^{\prime}\right)=$ the concentration of ${ }^{137} \mathrm{Cs}$ for any cumulative mass depth $x$ and time $t^{\prime}\left(\mathrm{Bq} \mathrm{kg}{ }^{-1}\right)$;

$D=$ the effective diffusion coefficient $\left(\mathrm{kg}^{2} \mathrm{~m}^{-4}\right.$ year $\left.{ }^{-1}\right)$;

$H=$ relaxation depth of the initial distribution of the fallout ${ }^{137} \mathrm{Cs}$ expressed as a mass depth $\left(\mathrm{kg} \mathrm{m}^{-2}\right)$;

$\lambda=$ the decay constant for ${ }^{137} \mathrm{Cs}\left(0.023\right.$ year $\left.{ }^{-1}\right)$;

$x=$ the mass depth from the soil surface downwards $\left(\mathrm{kg} \mathrm{m}^{-2}\right)$;

$t=$ the time since the first deposition of ${ }^{137} \mathrm{Cs}$ (year);

$I\left(t^{\prime}\right)=$ the input $\left(\mathrm{Bq} \mathrm{m}^{-2}\right.$ year $\left.^{-1}\right)$ at time $t^{\prime}$.

The model converts the magnitude of the reduction or increase in the ${ }^{137} \mathrm{Cs}$ inventory, relative to the reference inventory, to an estimate of the rate of soil loss or deposition for uncultivated sites. Further details of this model can be found in Porto et al. (2003).

\section{Estimating erosion and deposition rates using the ${ }^{137} \mathrm{Cs}$ measurements obtained for the sampling points within the study catchment}

The diffusion and migration model described above was parameterized using the reference profile depicted in Fig. 3(a). The ranges for erosion and deposition rates estimated for the individual sampling points within the study catchment, based on the ${ }^{137} \mathrm{Cs}$ measurements, are presented in Fig. 4.
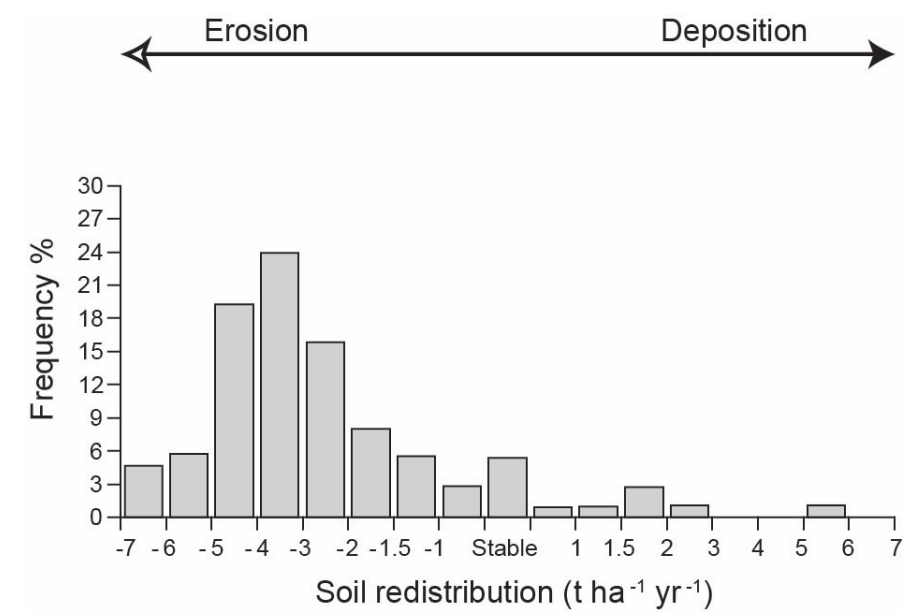

Fig. 4 The range of erosion and deposition rates $\left(\mathrm{t} \mathrm{ha}^{-1}\right.$ year $\left.{ }^{-1}\right)$, estimated using the ${ }^{137} \mathrm{Cs}$ measurements obtained for the sampling points within the study catchment.

The central class, designated stable, represents those sampling points where the measured inventories fell within the uncertainty range associated with the reference inventory. These results emphasise both the appreciable rates of erosion associated with most of the sampling points and that although the specific sediment yield from the study catchment, which is estimated to be 
approx. $0.4 \mathrm{t} \mathrm{ha}^{-1}$ year $^{-1}$ is relatively low, there is clear evidence of active erosion within the catchment. Many of the estimated erosion rates are an order of magnitude greater than those based on estimated specific sediment yield.

\section{DISCUSSION}

The results reported in Table 1 and Fig. 4 clearly indicate that erosion is dominant throughout the catchment. However, the presence of depositional zones, and the relatively low sediment yield measured at the catchment outlet, emphasise that a substantial portion of the sediment mobilised within the catchment by erosion is redistributed within the catchment rather than removed from the area as suspended sediment. If the information provided by the 100 sampling points within the Melito catchment can be assumed to provide a representative sample of the magnitude of soil redistribution rates on the slopes of the catchment, these data can provide a basis for establishing a sediment budget for the catchment slopes. The relative incidence of sampling points providing evidence of deposition directly reflects the importance of the storage component within the sediment budget of the catchment slopes.

The sediment budget for the Melito catchment shown in Fig. 5 has been constructed using the general principles outlined by Porto et al. $(2011,2013 \mathrm{a}, \mathrm{b})$ in similar studies. As a first step, a value of the gross erosion ( $t$ year ${ }^{-1}$ ) associated with the catchment slopes was estimated. This estimate was derived as the product of the mean erosion rate for the sampling points characterized by erosion and the area of the catchment subject to erosion. The latter is derived as the product of the proportion of the 100 sampled points evidencing erosion and the catchment area.

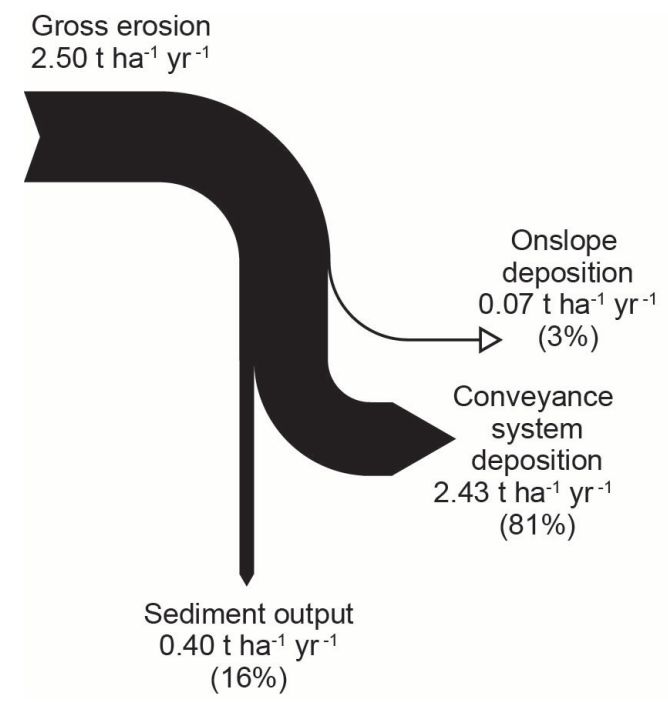

Fig. 5 Schematic sediment budget for the Melito catchment.

The same approach was applied to derive an estimate of total deposition on the slopes of the catchment. The second step involves subtracting an estimate for total deposition within the catchment from gross erosion to provide an estimate of net erosion, which here is interpreted to represent the sediment delivered to the channel system. The final step involves calculating the amount of sediment deposited and stored within the main channel system and on the flood plains bordering the channel. This is derived as the difference between the net erosion from the slopes, and the mean annual sediment output from the catchment. The latter is provided by the sediment yield data available for the catchment outlet for the period 1962-1977, assuming that these are representative of the period to which the soil redistribution rates estimated from the ${ }^{137} \mathrm{Cs}$ measurements relate (i.e. c. 1954-2010). This estimate is seen to represent the conveyance loss that occurs between sediment delivery to the channel and the catchment outlet. 
The estimates of gross and net erosion, and deposition and conveyance loss presented in Fig. 5 relate to the total catchment area, but have been expressed as values per unit area $\left(\mathrm{t} \mathrm{ha}^{-1} \mathrm{year}^{-1}\right)$. The estimate of gross erosion for the catchment, shown in Fig. 5, is $\sim 2.5 \mathrm{t} \mathrm{ha}^{-1}$ year $^{-1}$. This value is relatively low and probably reflects the large area of the catchment covered by forest that can be expected to keep erosion rates low. Figure 5 also indicates that onslope deposition is very low and accounts only for $\sim 0.07 \mathrm{tha}^{-1}$ year $^{-1}$, corresponding to approximately $3 \%$ of the gross erosion. This result is not unexpected because the steep slopes dominating the catchment (Fig. 1) offer very limited opportunities for the sediment mobilised upslope, to be redeposited before reaching the channel system.

In contrast, the sediment storage associated with the channel conveyance system accounts for $\sim 2.03 \mathrm{t} \mathrm{ha}^{-1}$ year $^{-1}$, representing about $81 \%$ of the gross erosion. This result emphasises that most of the sediment eroded upslope is deposited within the channel system, which is characterised by relatively low gradients and significant areas of flood plain. Considering the gross erosion rate associated with the catchment slopes, and the proportion of sediment entering storage both on the slopes of the catchment and in the channel and flood-plain system, the sediment delivery ratio for the catchment is about $16 \%$. Since the estimate of deposition within the channel and flood plain system, and thus the conveyance loss represented in Fig. 5, has been calculated by subtracting the measured sediment yield at the catchment outlet from the net soil loss derived from the catchment slopes, the sediment budget reported in this paper must be seen as preliminary. Further work is required to confirm the amount of sediment being sequestered by the flood plains and confirm their role as a sediment sink. This could again be achieved using ${ }^{137} \mathrm{Cs}$ measurements (see Walling $\& \mathrm{He}, 1997,1999)$. However, it was not possible to undertake sampling on the flood plains bordering the main channel system during the recent period because of the dam construction in progress. Additional field sampling on the flood plains is planned once construction of the hydraulic structures has been completed. In addition, it should be recognised that the budget presented in Fig. 5 takes no account of additional inputs of sediment to the channel system from channel erosion. If this is significant, it will further increase the conveyance loss, and reduce the sediment delivery ratio of $16 \%$. Channel erosion is currently assessed to be of limited importance, but this needs further confirmation using sediment source fingerprinting techniques (e.g. Walling, 2005).

As indicated above, another important potential limitation of the sediment budget presented in Fig. 5 relates to the fact that the periods covered by the measured sediment yield and the estimates of soil redistribution rates are different. The estimates of soil redistribution provided by the ${ }^{137} \mathrm{Cs}$ measurements relate to a period of approx. 56 years, extending from the commencement of fallout (1954) to the time of sampling (2010), whereas the sediment yield-monitoring programme at the catchment outlet covers only 16 years (extending from 1962 to 1977). Any comparison of the two sets of values must recognise the possibility of differences in erosion intensity between the two periods. In this context it is clearly important to consider the possible impacts of climate change, and changes in land use and population within the study catchment. Available evidence indicates that there has been no substantive change in land use or population within the study catchment over the period of interest. However, recent studies performed in southern Italy have documented an increasing trend in rainfall erosivity during the last 10-15 years (Porto \& Walling, 2012). This suggests that in recent years soil erosion rates may have increased relative to those existing during the period represented by the measurements of sediment yield at the catchment outlet (19621977).

\section{CONCLUSIONS}

The results presented in this contribution demonstrate the potential for using ${ }^{137} \mathrm{Cs}$ measurements to assemble information on soil erosion and sediment redistribution rates within a medium-sized catchment in southern Italy. The estimates of gross and net erosion on the catchment slopes, provided by a systematic ${ }^{137} \mathrm{Cs}$ sampling programme, have been related to the measured sediment output from the catchment to establish a tentative sediment budget. The sediment budget con- 
structed for the Melito catchment demonstrates that the specific sediment yield measured at the catchment outlet does not provide a good indication of the intensity of erosion on the slopes of the catchment. The estimates of erosion rates on the slopes of the catchment are nearly an order of magnitude greater than the sediment yield. Similar results were obtained in previous studies carried out in Calabria (see Porto et al., 2009b, 2013a,b). This situation suggests that sediment storage, associated with flood plains and channel transfer pathways represents a key component of the sediment budget, and exerts an important control on downstream sediment yields.

Acknowledgements The study reported in this paper was supported by grants from MIUR PRIN 2010-2011, and by IAEA (Technical Contract 15478).

\section{REFERENCES}

Cinnirella, S., Iovino, F., Porto, P. \& Ferro, V. (1998) Anti-erosive effectiveness of Eucalyptus coppices through the cover management factor estimate, Hydrol. Processes 12, 635-649.

Di Stefano, C., Ferro, V. \& Porto, P. (2000) Length slope factors for applying the Revised Universal Soil Loss Equation at basin scale in Southern Italy, J. Agric. Engng Res.75(4), 349-364.

Owens, P.N. \& Walling, D. E. (1996) Spatial variability of caesium-137 inventories at reference sites: an example from two contrasting sites in England and Zimbabwe. Appl. Radiat. Isotopes 47, 699-707.

Porto, P. \& Walling, D. E. (2012) Validating the use of ${ }^{137} \mathrm{Cs}$ and ${ }^{210} \mathrm{~Pb}_{\mathrm{ex}}$ measurements to estimate rates of soil loss from cultivated land in Southern Italy. J. Environ. Radioactiv 106, 47-57.

Porto, P., Walling, D. E. \& Callegari, G. (2009a) Investigating the effects of afforestation on soil erosion and sediment mobilisation in two small catchments in Southern Italy. Catena 79, 181-188.

Porto, P., Walling, D. E. \& Callegari, G. (2011) Using ${ }^{137}$ Cs measurements to establish catchment sediment budgets and explore scale effects. Hydrol. Processes 25, 886-900.

Porto, P., Walling, D. E. \& Callegari, G. (2013a) Using ${ }^{137} \mathrm{Cs}$ and ${ }^{210} \mathrm{~Pb}_{\mathrm{ex}}$ measurements to investigate the sediment budget of a small forested catchment in southern Italy. Hydrol. Processes 27, 795-806.

Porto, P, Walling, D. E., Callegari, G. \& Capra, A. (2009b) Using caesium-137 and unsupported lead-210 measurements to explore the relationship between sediment mobilisation, sediment delivery and sediment yield for a Calabrian catchment. Mar. Freshwater Res.60, 680-689.

Porto, P, Walling, D. E., Callegari, G. \& Catona, F. (2006) Using fallout lead-210 measurements to estimate soil erosion in three small catchments in Southern Italy. Water, Air, and Soil Pollution: Focus 6, 657-667.

Porto, P., Walling, D. E. \& Ferro, V. (2001) Validating the use of caesium-137 measurements to estimate soil erosion rates in a small drainage basin in Calabria, southern Italy. J. Hydrol. 248, 93-108.

Porto, P., Walling, D. E., Ferro, V. \& Di Stefano, C. (2003) Validating erosion rate estimates by caesium-137 measurements for two small forested catchments in Calabria, Southern Italy. Land Degrad. Dev. 14, 389-408.

Porto, P., Walling, D. E. \& La Spada, C. (2013b) Using caesium-137 measurements to establish a sediment budget for the catchment of a small reservoir in southern Italy. In: Considering Hydrological Change in Reservoir Planning and Management (ed. by A. Schumann). IAHS Publ. 362, 125-133. IAHS Press, Wallingford, UK.

Servizio Idrografico e Mareografico Nazionale - SIMI (1920-2000) Annali Idrologici, Sezione di Catanzaro. Istituto Poligrafico dello Stato: Rome, Italy.

Walling, D. E. (1998) Use of ${ }^{137} \mathrm{Cs}$ and other fallout radionuclides in soil erosion investigations: Progress, problems and prospects. In: Use of ${ }^{137} \mathrm{Cs}$ in the Study of Soil Erosion and Sedimentation, 39-62, IAEA-TECDOC-1028, International Atomic Energy Agency, Vienna, Austria.

Walling, D.E. (2005) Tracing suspended sediment sources in catchments and river systems. Sci. Total Environ. 344, $159-184$.

Walling, D. E. \& He, Q. (1997) Use of fallout ${ }^{137} \mathrm{Cs}$ in investigations of overbank sediment deposition on river floodplains. Catena 29, 263-282.

Walling, D. E. \& He, Q. (1999) Improved models for estimating soil erosion rates from cesium-137 measurements. J. Environ. Qual. 28(2), 611-622.

Walling, D. E., He, Q. \& Appleby, P. C. (2002) Conversion models for use in soil-erosion, soil-redistribution, and sedimentation investigations. In: Handbook for the Assessment of Soil Erosion and Sedimentation using Environmental Radioactivity (ed. F. Zapata). Kluwer Academic Publishers: Dordrecht, The Netherlands, 111-164.

Walling, D. E. \& Quine, T. A. (1993) The use of fallout radionuclides in soil erosion investigations. In: Nuclear Techniques in Soil-Plant Studies for Sustainable Agriculture and Environmental Preservation, 597-619. Publication ST1/PUB/947, International Atomic Energy Agency, Vienna, Austria. 